\title{
Assessment and Analysis of Lifestyle Disease Burden in Tribes of Central India
}

\section{Kshitij RB Singh, Manuel Fernandes, Tanushri Sarkar and Parikipandla Sridevi ${ }^{\star}$}

Department of Biotechnology, Indira Gandhi National Tribal University, India

\section{Abstract \\ Background}

Rapid development of mankind has led to progress but has also been enduring uncountable lifestyle diseases. Emerging technologies has drastic change in day-to-day routines of people, consequences being multiple life-style diseases. Reports suggest high mortality worldwide owing to lifestyle diseases. Our study highlights the comparison of tribes of Central India with urban population of Amarkantak on assessment and analysis of lifestyle diseases.

\section{Methods}

In a cross-sectional study the data from sample size of 500 by random sampling was considered for the study and a well validated questionnaire was administered. Data collected relating to lifestyle risk factors and diseases were analyzed using SPSS vs 20 .

\section{Results}

Prevalence of overall lifestyle diseases in our study area was $53.5 \%$. Our observations were, gastrointestinal complications are the most common $125(25 \%)$, followed by diabetes $120(24 \%)$, hypertension $100(20 \%)$, rectal problems $75(15 \%)$, and renal calculi $20(4 \%)$. Further, a significant association of other risk factors were studied along with lifestyle diseases is reported.

\section{Conclusions}

Results obtained signify the adverse behavior of rural population regarding health necessities. Early detection and tracking of risk factors can reduce the occurrence of lifestyle diseases. A popula-

*Corresponding author: Sridevi P, Department of Biotechnology, Indira Gandhi National Tribal University, Amarkantak-484887, MP, India, Tel: +91 9630036673; +91 9407331673, E-mail: psridevi@igntu.ac.in

Citation: Singh K RB, Fernandes M, Sarkar T, Sridevi P (2019) Assessment and Analysis of Lifestyle Disease Burden in Tribes of Central India. J Infect Non Infect Dis 4: 027.

Received: October 1, 2019; Accepted: November 10, 2019; Published: November 18, 2019

Copyright: (c) 2019 Singh K RB, et al. This is an open-access article distributed under the terms of the Creative Commons Attribution License, which permits un $\neg$ restricted use, distribution, and reproduction in any medium, provided the original author and source are credited. tion-based program of screening of lifestyle diseases may be beneficial for the prevention of non-communicable diseases.

Keywords: Lifestyle diseases; Lifestyle risk factors; Non-Communicable diseases; Nutritional habits; Tribal population.

\section{Introduction}

Lifestyle is a way in which an individual cope himself physically, socially, psychologically, and economically through day to day that is incredibly vital. Lifestyle disturbances results in physical limitations and if are overlooked can develop into non-communicable diseases. Lifestyle diseases are characterized on the basis of prevalence on daily habits of individuals and are fallouts of an inappropriate relationship of individuals with their surroundings. Various factors contribute to lifestyle diseases, most importantly unhealthy food habits, physical inactivity, disturbed biological clock, and inappropriate body posture [1].

India is among the fastest developing country in the world and with this rapid development, it has left behind people with uncountable diseases. These diseases generally are of two type's communicable or non-communicable diseases (NCDs). NCDs can also be called as lifestyle diseases. Few to name are diabetes, cancer, cardiovascular diseases, blood pressure/hypertension, etc. In $2016,63 \%$ of the total death in India was due to NCDs $[2,3]$ and from the total death worldwide, 35 million individuals died of NCDs in 2005 [4] and according to WHO data of 2016 from total death worldwide, 40.5 million individuals died of NCDs [5], this number of death due to NCDs/lifestyle diseases are increasing year by year, lifestyle diseases. Physical inactivity and consumption of tobacco, cigarettes and alcohol can also lead to lifestyle diseases [6].

With increased urbanization and rapid development in the past few years the increase in these diseases has reached disturbing proportion, in the recent years, among Indians [7]. NCDs have not only become a major health problem in urban but also in rural population inhabitants [8]. In the general population, NCDs are common among the poor and young segments. The decline in communicable diseases and increase in chronic NCDs, due to epidemiological transition is occurring in many states of India [9]. Recent information collected from several sources show a higher risk of NCDs in rural population and people with weak socioeconomic standing which indicates that the pattern of the disease is changing from wealthy to the deprived $[10,11]$.

The area of study, Amarkantak is situated in central India, which is famous for its medicinal herbs and ethno-medicinal practices. Thus, the population residing in this region is more apprehensive about allopathy over Ayurveda. Moreover, this area being rich in bauxite ore [12] might contain high amount of heavy metals such as aluminum, lead, fluoride, iron which might be the main reason for aches in the inhabitants. In most of the backward regions and urban slums, rural medical practitioner (RMP-rural medical practitioner) is preferred for medication over reaching Govt. health system [13]. 
Citation: Singh K RB, Fernandes M, Sarkar T, Sridevi P (2019) Assessment and Analysis of Lifestyle Disease Burden in Tribes of Central India. J Infect Non Infect Dis 4: 027.

- Page 2 of $7 \bullet$

Our study emphasizes correlation between the type of disease and preferable medical practitioner by the patient. This "assessment and analysis of lifestyle disease burden in tribes of central India", is based on comparative study involving tribal village population and IGNTU campus residents (satellite population), and lifestyle disease parameters were considered to conclude lifestyle disease prevalence in the selected population. And further we have tried to proofread lifestyle risk factors in our population based comparative case study on lifestyle/non-communicable/chronic diseases and to know the lifestyle disease burden among rural population.

\section{Methods}

The present study is a cross-sectional study, conducted in Amarkantak region, Anuppur district, Madhya Pradesh, India. Rural population of this locality consists of satellite residents (residents' native of different regions but residing at Amarkantak due to service) as well as native residents of the villages in and around Amarkantak are listed.

\section{Study period}

The period of study was 4 months from February to June 2019 .

\section{Sample size}

From the 500 respondents, data was collected from 200 urban and 300 rural respondents.

\section{Sampling method}

Random sampling was conducted by taking sample from every 10 th person as a subject and the age group of the samples is more than 18 years only.

\section{Methodology}

After detailed study of this region, few parameters were assessed and analyzed to decide the burden of lifestyle diseases, and also to gain comparative information about urban and rural population among locality. The urban population of the locality completely consists of satellite residents (such inhabitants those are natively from urban areas but are residing here due to service) and the rural population consists of native residents of the village. Then survey material was developed i.e., questionnaire-preparation of questionnaire is based on lifestyle diseases. The questionnaire is strictly dependent on the parameters that are the nutshell of the project and length of Questionnaire is around 30 questions as there are evidences that longer surveys can diminish response rates Annexure I [14]. The questionnaire was prepared in English and vernacular or regional language. Ethics were prime concern of our project and hence we promise not to leak or share anyone's personal information. Ethical clearance was obtained from Institutional Ethics Committee. Before going to start the main survey, we conducted a pilot survey (Table 1) to test the significance of the questions prepared. The data collected during pilot survey was analyzed by performing statistical analysis i.e., ANOVA analysis, Chi-square test, Student-t test, Mean, Frequency, etc. and got positive results. Therefore, to observe the risk of lifestyle diseases and prevalence of lifestyle diseases within the tribal population of Amarkantak region, two villages that are extremely populated according to the information of voter list [15] of this region were selected and data was collected by random sampling, taking sample from every 10th individual.

\begin{tabular}{|l|c|}
\hline \multicolumn{1}{|c|}{ Pilot survey Parameters } & Sample for pilot survey \\
\hline Diseased population & $\mathbf{2 0}$ \\
\hline Appropriate lifestyle & \\
\hline Inappropriate lifestyle \\
\hline Alcohol/Caffeine/Tobacco consumption \\
Table 1: Pilot-Survey details. \\
\hline
\end{tabular}

The complete random survey stands on the following parameters physical status, nutritional habits, diseased population, appropriate and inappropriate lifestyle, gadgets utilization, superstitious believes and alcohol/caffeine/tobacco consumption. Seven parameters were considered and further tried to evaluate for most common disease, people prone to lifestyle diseases, comparison of lifestyle diseases in satellite and local rural population, and RMP (Rural Medical Practitioner) practices correlation with medical issues they will result in the population. Hence, to obtain unbiased result 500 subjects were selected at random and assessed based on 7 parameters. Similar study was conducted by [6] entitled 'Lifestyle factors and lifestyle diseases among rural population of Bengaluru rural district', is a major reference aiding our research topic 'Assessment and Analysis of Lifestyle Disease burden in tribes of Central India'. The main reason behind choosing this study was almost all the parameters which were selected for study were sophisticatedly covered in this study. Before going for the survey few hypotheses were framed to be tested.

1. Rural population suffers less from lifestyle diseases when compared to urban population.

2. Urban population has more appropriate nutritional habits when compared to rural population.

3. More than $50 \%$ of population prefers ethno-medicine.

4. Diabetes is a gender specific disorder.

5. Rural population suffers from physical limitation when compared to urban population.

6. $50 \%$ or more population suffers from lifestyle diseases.

7. Alcohol and tobacco addiction are more in rural population.

8. Burden of thyroid disorders varies in different age group.

After hypothesis was framed data was collected by conducting personal interviews and health education was also given simultaneously to the respondents regarding lifestyle diseases risk factors after interview. Data regarding socio-demographic profile (sex, date of birth, ethno medicinal practices, and superstitious belief), nutritional habits, medical issues (cross verified by taking doctor's prescription), RMP practices, medical screening, gadgets utilization, alcohol/cigarette/tobacco consumption, and regular physical activity was collected. The data was entered in MS Excel spreadsheet as well as in SPSS spreadsheet and analyzed based on the framed hypothesis and set parameters using mean and proportion, Chi-square test, ANOVA (One way ANOVA), and Student t-test (Independent sample t-test) analysis was performed with the help of statistical software SPSS vs 25 and $\mathrm{P}$-value of $<0.05$ was considered as significant with $95 \%$ confidence level. 
Citation: Singh K RB, Fernandes M, Sarkar T, Sridevi P (2019) Assessment and Analysis of Lifestyle Disease Burden in Tribes of Central India. J Infect Non Infect Dis 4: 027.

- Page 3 of 7 •

\section{Results}

By considering the eight hypotheses given in methodology, the $8^{\text {th }}$ hypothesis that is 'Burden of thyroid disorder varies in different age group' was not significant with P-value of 0.215 which is more than 0.05 in ANOVA test, so this hypo was not significant when the margin of error was $5 \%$ and confidence level was $95 \%$ and the result can be concluded that thyroid burden is not age dependent disorder. The results suggested seven out of eight were supporting null hypothesis and has highly significant $\mathrm{p}$-value as given under.

1. 'Rural population suffers less from lifestyle diseases when compared to urban population' has a P-value of 0.000 with 0.056 standard error difference in independent sample T-test.

2. 'Urban population has more appropriate nutritional habits when compared to rural population' has a P-value of .000 with .066 standard error difference in chi-square and independent sample t-test.

3. 'More than $50 \%$ of population prefers ethno-medicine' has a $\mathrm{P}$-value of 0.000 in chi-square test.

4. 'Diabetes is a gender specific disorder' has significant P-value of 0.015 with 0.035 standard error difference in chi-square and independent sample t-test.

5. 'Rural population suffers from physical limitation when compared to urban population' has a P-value of 0.000 with 0.228 standard error difference in independent sample t-test.

6. ' $50 \%$ or more population suffers from lifestyle diseases' has significance value of 0.031 in ANOVA test.

7. 'Alcohol and tobacco addiction are more in rural population' has 0.008 P-value in ANOVA test.

The socio-demographic profile of society (both rural and urban) (Table 2), suggests out of the 500 study participants, 260 (52\%) were male and $240(48 \%)$ were females. Mean age of the participants was $37.12 \pm 4.06$ years. There was almost equal distribution of age groups. In the population, $80 \% \pm 0.401$ of population are involved in ethno-medicinal practices and $53 \% \pm 0.5$ in superstitious believes.

\begin{tabular}{|l|c|c|}
\hline \multicolumn{1}{|c|}{ Variables } & & Subjects (\%) \\
\hline Mean age & 37.12 & --- \\
\hline \multirow{2}{*}{ Sex } & Male & $260(52 \%)$ \\
\cline { 2 - 3 } & Females & $240(48 \%)$ \\
\hline \multirow{2}{*}{ Ethno medicinal practices } & Yes & $400(80 \%)$ \\
\cline { 2 - 3 } & No & $100(20 \%)$ \\
\hline \multirow{2}{*}{ Superstitious practices } & Yes & $265(53 \%)$ \\
\cline { 2 - 3 } & No & $235(47 \%)$ \\
\hline
\end{tabular}

Table 2: Socio-demographic profile.

Further, $68 \% \pm 0.46$ of the population was using electronic gadgets and $13.5 \% \pm 0.97$ of the population is having high utilization, $24 \%$ have moderate utilization, $30.5 \%$ low, and $32 \%$ no utilization of electronic gadgets (Table 3). When compared between, the urban population and rural population of Amarkantak, urban population has much better nutritional habits then rural population. As $12 \% \pm$ 0.064 i.e. 60 subjects of urban population consume 3 -time meals with healthy snacks but only $1 \% \pm 0.048$ i.e., 5 in rural population consumes 3 meals with healthy snacks (Table 4, Figure 1).

\begin{tabular}{|c|c|c|c|}
\hline Variables & Percentage & Frequency of utilization & Percent \\
\hline \multirow{2}{*}{ Yes } & \multirow{2}{*}{$68 \% \pm 0.46$} & High & $13.5 \% \pm 0.97$ \\
\cline { 3 - 4 } & & Moderate & $24 \% \pm 0.97$ \\
\hline \multirow{2}{*}{ No } & \multirow{2}{*}{$32 \% \pm 0.46$} & Low & $30.5 \% \pm 0.97$ \\
\cline { 3 - 4 } & & No utilization & $32 \% \pm 0.97$ \\
\hline
\end{tabular}

Table 3: Electronic gadget utilization status of population.

\begin{tabular}{|c|c|c|c|c|c|}
\hline \multicolumn{6}{|c|}{ Physical limitation status in rural and urban population } \\
\hline Population & Variable & \multicolumn{2}{|c|}{ Frequency (\%) } & P-value & Odd ratio \\
\hline \multirow{2}{*}{ Rural } & Yes & $245(49 \% \pm 0.3$ & & \multirow{4}{*}{$0.000^{*}$} & \multirow{4}{*}{6.68} \\
\hline & No & $55(11 \% \pm 0.38$ & & & \\
\hline \multirow{2}{*}{$\begin{array}{l}\text { Urban (Satellite } \\
\text { Population) }\end{array}$} & Yes & \multicolumn{2}{|c|}{$80(16 \% \pm 0.492)$} & & \\
\hline & No & \multicolumn{2}{|c|}{$120(24 \% \pm 0.492)$} & & \\
\hline \multicolumn{6}{|c|}{ Nutritional habit status in rural and urban population } \\
\hline Population & \multicolumn{2}{|c|}{ Variable } & \multicolumn{2}{|c|}{ Frequency (\%) } & P-value \\
\hline \multirow{4}{*}{ Rural } & \multicolumn{2}{|c|}{3 meals with healthy Snacks } & \multicolumn{2}{|c|}{$5(1 \% \pm 0.048)$} & \multirow{8}{*}{$0.000^{*}$} \\
\hline & \multicolumn{2}{|c|}{3 meals } & \multicolumn{2}{|c|}{$70(14 \% \pm 0.048)$} & \\
\hline & \multicolumn{2}{|c|}{2 meals or less } & \multicolumn{2}{|c|}{$180(36 \% \pm 0.048)$} & \\
\hline & \multicolumn{2}{|c|}{ No regular eating pattern } & \multicolumn{2}{|c|}{$45(9 \% \pm 0.048)$} & \\
\hline \multirow{4}{*}{$\begin{array}{l}\text { Urban (Satellite } \\
\text { Population) }\end{array}$} & \multicolumn{2}{|c|}{3 meals with healthy Snacks } & \multicolumn{2}{|c|}{$60(12 \% \pm 0.064)$} & \\
\hline & \multicolumn{2}{|c|}{3 meals } & \multicolumn{2}{|c|}{$130(26 \% \pm 0.064)$} & \\
\hline & \multicolumn{2}{|c|}{2 meals or less } & \multicolumn{2}{|c|}{$9(1.8 \% \pm 0.064)$} & \\
\hline & \multicolumn{2}{|c|}{ No regular eating pattern } & \multicolumn{2}{|c|}{$1(0.2 \% \pm 0.064)$} & \\
\hline
\end{tabular}

Table 4: Physical limitation and nutritional habit comparative study.

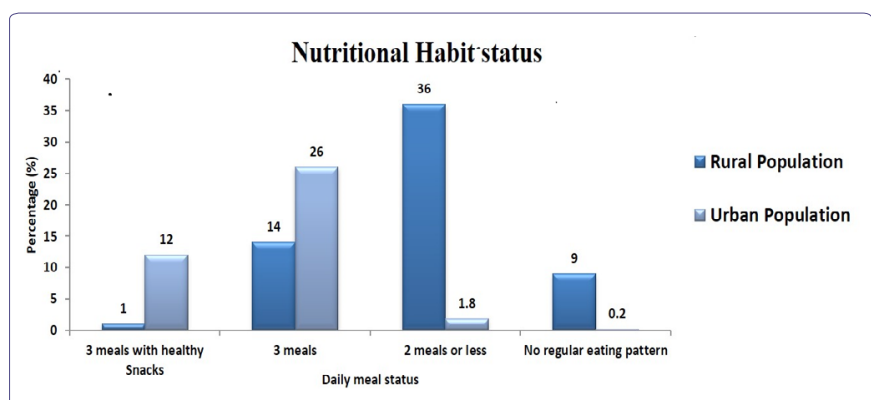

Figure 1: Comparative study between urban and rural population for nutritional habits.

In the population, $49 \% \pm 0.389$ of the rural population has physical limitation and when compared with the urban population it's too high as urban population has only $16 \% \pm 0.492$ (Table 4 ). The most common physical limitation is back pain in 85 subjects followed by leg pain, muscle pain, dizziness, joint pain, chest discomfort, torn ligament, shortness of breath, etc. (Figure 2).

From the analysis it was observed that $42 \% \pm 0.15$ of the rural population is not willing for health checkups and screening for common ailments, $3.4 \% \pm 0.15$ of the subjects have not gone for any health checkup within the last 5 years, and $39.2 \% \pm 0.16$ of the rural population prefers unauthorized medical practitioners in spite of health complications. But in the urban population only $0.6 \% \pm 0.14$ of the subjects prefer unauthorized medical practitioners (Table 5). 
Citation: Singh K RB, Fernandes M, Sarkar T, Sridevi P (2019) Assessment and Analysis of Lifestyle Disease Burden in Tribes of Central India. J Infect Non Infect Dis 4: 027.

\begin{tabular}{|c|c|c|c|c|c|}
\hline Options & Urban population & Rural population & Options & Urban population & Rural population \\
\hline \multirow{2}{*}{ Authorized medical practitioners } & \multirow{2}{*}{$197(39.4 \% \pm 0.14)$} & \multirow{2}{*}{$104(20.8 \% \pm 0.16)$} & Never went for health check-up & $30(6 \% \pm 0.13)$ & $210(42 \% \pm 0.15)$ \\
\hline & & & Not within the past 5 years & $1 \%(5 \pm 0.13)$ & $17(3.4 \% \pm 0.15)$ \\
\hline \multirow{2}{*}{ Unauthorized medical practitioners } & \multirow{2}{*}{$3(0.6 \% \pm 0.14)$} & \multirow{2}{*}{$196(39.2 \% \pm 0.16)$} & At least every 2 years & $23(4.6 \% \pm 0.13)$ & $15(3 \% \pm 0.15)$ \\
\hline & & & On an annual basis & $142(28.4 \% \pm 0.13)$ & $58(11.6 \% \pm 0.15)$ \\
\hline
\end{tabular}

Table 5: Medical screening status in population.

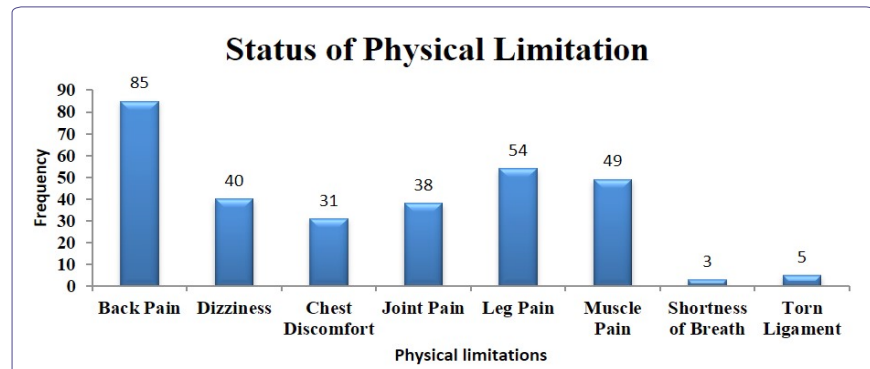

Figure 2: Physical Limitation status in the inhabitants of Amarkantak region.

The lifestyle risk factors like alcohol, tobacco, and smoking status of the population were analyzed separately and $41 \% \pm 0.039$ of subjects in the population found to be consuming tobacco, $33 \% \pm 0.136$ are alcohol consumers, $10.6 \% \pm 0.097$ are smokers, and $65 \% \pm 0.478$ of subject in the population are physically frail as they were suffering from physical limitations like back pain, leg pain, etc. (Table 6). These parameters are major contributors as risk factors for non-communicable diseases.

\begin{tabular}{|c|c|c|c|}
\hline \multicolumn{4}{|c|}{ Lifestyle risk factors } \\
\hline Risk Factor & \multicolumn{2}{|c|}{ Frequency $(\%)$} & P-value \\
\hline Alcohol consumption & \multicolumn{2}{|c|}{$165(33.0 \% \pm 0.136)$} & $0.000^{*}$ \\
\hline Cigarette Consumption & \multicolumn{2}{|c|}{$53(10.6 \% \pm 0.097)$} & $0.000^{*}$ \\
\hline Tobacco consumption & \multicolumn{2}{|c|}{$205(41.0 \% \pm 0.039)$} & $0.000^{*}$ \\
\hline Physical limitations & \multicolumn{2}{|c|}{$325(65 \% \pm 0.478)$} & $0.000^{*}$ \\
\hline \multicolumn{4}{|c|}{ Lifestyle Disease Status in Population } \\
\hline & Frequency & Percent & P-value \\
\hline Healthy Person & 85 & $17.0 \pm 0.672$ & \multirow{4}{*}{$.000^{*}$} \\
\hline Suffering from Lifestyle Diseases & 268 & $53.6 \pm 0.672$ & \\
\hline Prone to Lifestyle Diseases & 147 & $29.4 \pm 0.672$ & \\
\hline Total & 500 & & \\
\hline \multicolumn{4}{|c|}{ *Statistically significant difference from One-Sample T-test } \\
\hline
\end{tabular}

Table 6: Distribution of lifestyle risk factors and Lifestyle Disease Status in population.

Our study results show that, $53.6 \% \pm 0.672$ of the population is suffering from medical issues (Table 6). The most common medical issue in population is gastrointestinal in $125(25 \% \pm 0.0318)$ subjects, followed by diabetes in $120(24 \% \pm 0.0174)$ subjects, hypertension in $100(20 \% \pm 0.017)$ subjects, rectal problems in $75(15 \% \pm 0.025)$ subjects, thyroid in $60(12 \% \pm 0.016)$ subjects, renal calculi in $20(4 \%$ $\pm 0.013)$ subjects. Further, many other medical issues are also seen in the population with medical history i.e. in 268 subjects such as arthritis, cancer, high cholesterol, etc. in very less number (Figure 3).

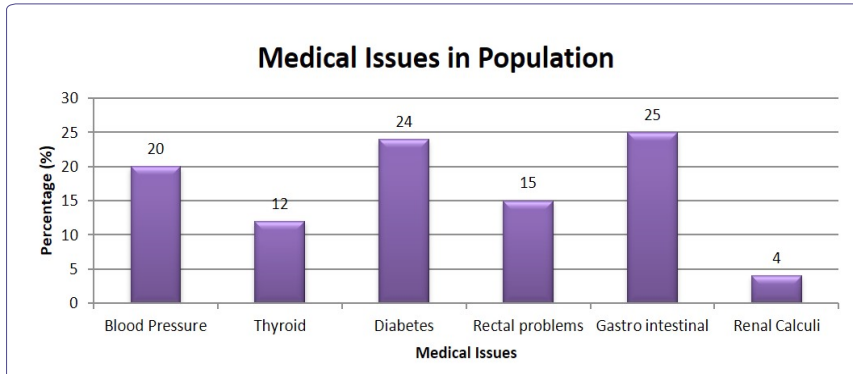

Figure 3: Medical Issue analysis from which most of the inhabitants suffer.

Finally, in the population only $17 \% \pm 0.672$ are healthy, $53.6 \%$ \pm 0.672 are suffering from lifestyle diseases, and $29.4 \% \pm 0.672$ are prone to lifestyle diseases based on the comparison of nutritional habits and physical limitations (Table 6).

\section{Discussion}

The present study emphasizes the previous report that chronic diseases key determinants are not inherited but lifestyle, diet, and environmental factors are mostly responsible, these diseases were previously common in high-income countries but now it's cause of disease and death worldwide [16]. In Central India from the analysis we understood that lifestyle factors can cause NCD/chronic diseases/lifestyle diseases are far above the ground and hence to reduce the prevalence of NCDs, attempts were made for awareness among the population to avoid tobacco use, to maintain a healthy weight, to maintain daily physical activity and limit gadget utilization, eat a healthy diet, and to avoid unauthorized medical practitioners. In contrast to urban population, rural population suffers more from physical limitations/physical inactivity, in view of the fact that chronic diseases are more prevalent in these populations and the further curing process has been deviated erroneously by local baidya or unauthorized medical practitioner as they lack proper knowledge and awareness $[13,17]$.

In a commentary [7] it's stated that there is a lack of epidemiological figures on the overall occurrence of lifestyle diseases in India for the reason that the country has diverse population with dissimilar social and cultural distinctiveness. Even now, there is inadequate access to govt healthcare facilities for many rural areas but most of the people in our study do not prefer govt healthcare system but due to their belief on indigenous healthcare systems i.e., ethno-medicinal and superstitious practices.

In 2008, approx. 1.7 million people died worldwide due to wrong nutritional habits [18]. In present study the rural population lacks proper nutrition which can further lead to lethal diseases like cancer, as improper diet can raise the risk of causing cancer. When examined, diet-related factors account for almost $30 \%$ of cancer. 
Alcohol consumption causes oral, liver, and small amount of risk for breast cancer and proper intake of fruits and vegetables reduces the risk of several types of cancer. So, it is advised to take proper nutrition which includes fruit, vegetables, and cereals to maintain a healthy bodyweight with regular physical activity and avoid consumption of alcohol [19].

In 2016, 3 million people died globally due to alcohol consumption [20]. In a study done in rural Tamil Nadu by Logaraj, et al., in 2014 [21], 16\% were consuming alcohol, in the present study, the incidence of people consuming alcohol and alcoholic products in rural region is quite high. And further, a study conducted in Delhi [22] shows $50.7 \%$ subject consuming alcohol which is higher than the current study result. From a study, it's elucidated that one death occurs every six seconds due to the use of tobacco and exposure to tobacco smoke (Tobacco control- Global Health Observatory [23]. Consumption of tobacco products in our area is much more as compared to the study done in 2013 by Bhagyalaxmi, et al., [24] in rural Gujarat where only $32 \%$ of subjects were consuming tobacco products. In an urban slum of Coimbatore [25] 39\% had smoking history which is much higher in comparison with our studied subjects.

In 2014 , globally around $8.5 \%$ of adults aged 18 and above had raised diabetes [26] and 1.13 billion people worldwide are affected by hypertension [27]. From the study at Delhi [22], the prevalence of hypertension was $36.9 \%$ and that of diabetes was $10.53 \%$. In Jamnagar [28] study, hypertension was reported in $33.5 \%$ and diabetes in $10.4 \%$ of study subjects. When these results are compared with the results of the current study the prevalence of hypertension is higher in these studies, possibly because these studies were done in urban areas, but diabetes is very highly reported in our study when compared with these studies.

The limitations of this study were language barrier but it was overcome by a translator and while collecting the data the village people were convinced to adopt a healthy lifestyle by spreading awareness among the villagers to avoid unauthorized medical practitioners and were encouraged to adopt healthy nutritional habits and physical fitness for healthy lifestyle.

\section{Conclusion}

The current survey concludes that the local rural population is healthier in comparison to the urban (satellite) population. The rural population hardly suffers from lifestyle diseases. But, the main reason behind physical limitations may be the contamination of heavy metals in water and improper nutritional habits. The major part of the rural population is not suffering from lifestyle diseases, it cannot be ruled out that, they are not prone to diseases like diabetes or cardiovascular diseases owing to improper eating habits along with low fruit and vegetable consumption and low nutritional quality may be due to socio-economic conditions.

Adopting a healthy lifestyle is a very good therapeutic tool for chronic diseases. Developing a therapeutic education communication tool can be the future of better health care management, which will fill the gap between recommendation and implementation for adopting good lifestyle practices [29]. Hypertension prevention can be effective for the management of Cardiovascular Disease (CVD) and other diseases such as dementia, cancer, etc. For the prevention of hypertension, there are few guidelines which include pharmacotherapy and non-pharmacotherapy along with lifestyle modifications [30]. Physical activity is the key to a healthy life and can prevent humans from many deadly chronic ailments. There is a multimodality intervention (e.g., low-saturated fat, plant-based, whole-food diets with exercise, and stress reduction) which has the best significance for the prostate cancer treatment and many other diseases too, but there is a very urgent need to develop a way to implement the interventions into real-world for practice [31]. Metabolic syndromes, cancer, diabetes, and dementia are increasing at an alarming rate and there is a very urgent need to develop better health care management tools/strategies and medicine for lifestyle diseases as personalized treatment, prevention, and disease management is the cornerstone of the future [32]. Weight management can also help to reduce many chronic ailments by diet modifications, physical activity, and behavior change therapies [33].

Our study emphasizes that early detection and tracking of risk factors can reduce the occurrence of lifestyle diseases. The rural population is unwilling for medical screening. As a result, the rural population though suffers from more physical limitations, and which can be early symptoms for lifestyle diseases are thus ignored. Our observations pertaining to the urban (satellite) population emphasizes the presence of lifestyle diseases but has ruled out for physical limitations when compared with the rural population.

Hence, our work highlights the need for population-based screening programs and also awareness and counseling series even from the primary level (households) among the rural population which will help the rural population to adopt a healthy routine and prevent them from these lifestyle diseases.

\section{Acknowledgement}

The authors would like to extend their gratitude of thanks to Dr. S. Balaswamy of Department of Statistics, Indira Gandhi National Tribal University, for helping in statistical analysis as well as Sree Lekshmi K. K for helping in literature review.

\section{Author Contributions}

Dr. Parikipandla Sridevi has designed the study and helped in analysis of data and writing the manuscript. Kshitij RB Singh has contributed to collection of data, data interpretation, literature search, and writing. Tanushri Sarkar contributed to data collection, and interpretation. Manuel Fernandes has contributed to data collection, and writing.

\section{Funding: None.}

\section{Competing interests: No conflict of interest.}

Ethical approval: Ethical clearance was obtained from Institutional Ethics Committee.

\section{References}

1. Sharma M, Majumdar PK (2009) Occupational lifestyle diseases: An emerging issue. Indian J Occup Environ Med 13: 109-112.

2. World Health Organization (2018) Noncommunicable Diseases Country Profile.

3. World Health Organization (2014) Global status report on noncommunicable diseases. 
Citation: Singh K RB, Fernandes M, Sarkar T, Sridevi P (2019) Assessment and Analysis of Lifestyle Disease Burden in Tribes of Central India. J Infect Non Infect Dis 4: 027.

4. Preventing Noncommunicable Diseases in the Workplace through Diet and Physical Activity WHO/World Economic Forum Report of a Joint Event (2008).

5. Noncommunicable diseases (NCD) Global Health Observatory (GHO) data.

6. Deepadarshan H, Shweta D Hiremath (2017) Lifestyle factors and lifestyle diseases among rural population of Bengaluru rural district. IJCMPH 4: 1558-1561.

7. Pappachan MJ (2011) Increasing prevalence of lifestyle diseases: High time for action. Indian J Med Res 134: 143-145.

8. Srinath Reddy K, Shah B, Varghese C, Ramadoss A (2005) Responding to the threat of chronic diseases in India. Lancet 366: 1744-1749.

9. Gupta R, Al-Odat NA, Gupta VP (1996) Hypertension epidemiology in India: meta-analysis of 50 year prevalence rates and blood pressure trends. J Hum Hypertens 10: 465-472.

10. Whiting D, Unwin N, Roglic G (2010) Equity, social determinants and public health programmes. In: Erik Blas, Anand Sivasankara Kurup (eds.). Diabetes: equity and social determinants.

11. Jeemon P, \& Reddy KS (2010) Social determinants of cardiovascular disease outcomes in Indians. Indian J Med Res 132: 617-622.

12. Mineral and Energy Resources (2019). In: India People and Economy. 72-84.

13. Prasada Rao U, Samson Sanjeeva Rao N (2017) THE RURAL MEDICAL PRACTITIONER OF INDIA. Journal of Evolution of Medical and Dental Sciences 6: 5321-5323.

14. Ruth C Engs (1991) Student Health and Lifestyle Questionnaire. IU ScholarWorks.

15. Voter list of Janpad Panchayat -Pushparajgarh, district-Anuppur (2018)

16. Walter C Willett, Jeffrey P Koplan, Rachel Nugent, Courtenay Dusenbury, Pekka Puska, et al. (2006) Prevention of Chronic Disease by Means of Diet and Lifestyle Changes. In: DT Jamison, JG Breman, AR Measham, G Alleyne, M Claeson, DB Evans, P Musgrove (Eds.). Disease Control Priorities in Developing Countries. (2nd edn), pg.no: 833-850.

17. Booth FW, Roberts CK, Laye MJ (2012) Lack of Exercise Is a Major Cause of Chronic Diseases. In: Comprehensive Physiology.

18. WHO (2019) Unhealthy diet- Global Health Observatory (GHO) data.

19. Key TJ, Allen NE, Spencer EA, Travis RC (2002) The effect of diet on risk of cancer. The Lancet 360: 861-868.
20. WHO (2019) Global Information System on Alcohol and Health (GISAH)- Global Health Observatory (GHO) data.

21. Logaraj M, Hegde SK, John K, Balaji R (2014) A study on risk factors for lifestyle diseases among patients attending fixed mobile clinic in a rural block in Tamil Nadu. International Journal of Health \& Allied Sciences 3: 199-203.

22. Laskar A, Sharma N, Bhagat N (2010) Lifestyle disease risk factors in a north Indian community in delhi. Indian Journal of Community Medicine 35: 426-428.

23. WHO (2019) Tobacco control- Global Health Observatory (GHO) data.

24. Bhagyalaxmi A, Atul T, Shikha J (2013) Prevalence of risk factors of non-communicable diseases in a District of Gujarat, India. Journal of Health, Population, and Nutrition 31: 78-85.

25. Hamsaa Nandini S, Karthikeyan S (2016) An educational intervention on the risk factors of lifestyle diseases among men aged 30-50 years in an urban slum in Coimbatore, Tamil Nadu, India. International Journal of Community Medicine and Public Health 4- 181.

26. WHO (2019) Blood Glucose- Global Health Observatory (GHO) data.

27. WHO (2019) Blood Pressure-Global Health Observatory (GHO) data.

28. Sochaliya KM, Parmar DV, Yadav SB (2012) A Study on Prevalence of Life-Style Diseases and Its Risk Factors in Urban Area of Jamnagar City. National Journal of Community Medicine 3: 595-600

29. Singer J (2018) Therapeutic Education for Healthy Lifestyle: How to Empower Your Patient and Increase Adherence. Reference Module in Food Science.

30. Kokubo Y, Matsumoto C (2018) Comprehensive Lifestyle Modification for Hypertension and Lifestyle-Related Disease under the New Guidelines. Encyclopedia of Cardiovascular Research and Medicine 651-658.

31. Zuniga KB, Chan JM, Ryan CJ, Kenfield SA (2019) Diet and lifestyle considerations for patients with prostate cancer. Urologic Oncology: Seminars and Original Investigations.

32. Abe M, Abe H (2019) Lifestyle medicine- An evidence based approach to nutrition, sleep, physical activity, and stress management on health and chronic illness. Personalized Medicine Universe 8: 3-9.

33. Kushner RF (2018) Weight Loss Strategies for Treatment of Obesity: Lifestyle Management and Pharmacotherapy. Prog Cardiovasc Dis 61: 246-252. 


\section{II \\ HERALD}

Journal of Anesthesia \& Clinical Care

Journal of Addiction \& Addictive Disorders

Advances in Microbiology Research

Advances in Industrial Biotechnology

Journal of Agronomy \& Agricultural Science

Journal of AIDS Clinical Research \& STDs

Journal of Alcoholism, Drug Abuse \& Substance Dependence

Journal of Allergy Disorders \& Therapy

Journal of Alternative, Complementary \& Integrative Medicine

Journal of Alzheimer's \& Neurodegenerative Diseases

Journal of Angiology \& Vascular Surgery

Journal of Animal Research \& Veterinary Science

Archives of Zoological Studies

Archives of Urology

Journal of Atmospheric \& Earth-Sciences

Journal of Aquaculture \& Fisheries

Journal of Biotech Research \& Biochemistry

Journal of Brain \& Neuroscience Research

Journal of Cancer Biology \& Treatment

Journal of Cardiology: Study \& Research

Journal of Cell Biology \& Cell Metabolism

Journal of Clinical Dermatology \& Therapy

Journal of Clinical Immunology \& Immunotherapy

Journal of Clinical Studies \& Medical Case Reports

Journal of Community Medicine \& Public Health Care

Current Trends: Medical \& Biological Engineering

Journal of Cytology \& Tissue Biology

Journal of Dentistry: Oral Health \& Cosmesis

Journal of Diabetes \& Metabolic Disorders

Journal of Dairy Research \& Technology

Journal of Emergency Medicine Trauma \& Surgical Care

Journal of Environmental Science: Current Research

Journal of Food Science \& Nutrition

Journal of Forensic, Legal \& Investigative Sciences

Journal of Gastroenterology \& Hepatology Research

Journal of Gerontology \& Geriatric Medicine

Journal of Genetics \& Genomic Sciences

Journal of Hematology, Blood Transfusion \& Disorders

Journal of Human Endocrinology

Journal of Hospice \& Palliative Medical Care

Journal of Internal Medicine \& Primary Healthcare

Journal of Infectious \& Non Infectious Diseases

Journal of Light \& Laser: Current Trends

Journal of Modern Chemical Sciences

Journal of Medicine: Study \& Research

Journal of Nanotechnology: Nanomedicine \& Nanobiotechnology

Journal of Neonatology \& Clinical Pediatrics

Journal of Nephrology \& Renal Therapy

Journal of Non Invasive Vascular Investigation

Journal of Nuclear Medicine, Radiology \& Radiation Therapy

Journal of Obesity \& Weight Loss

Journal of Orthopedic Research \& Physiotherapy

Journal of Otolaryngology, Head \& Neck Surgery

Journal of Protein Research \& Bioinformatics

Journal of Pathology Clinical \& Medical Research

Journal of Pharmacology, Pharmaceutics \& Pharmacovigilance

Journal of Physical Medicine, Rehabilitation \& Disabilities

Journal of Plant Science: Current Research

Journal of Psychiatry, Depression \& Anxiety

Journal of Pulmonary Medicine \& Respiratory Research

Journal of Practical \& Professional Nursing

Journal of Reproductive Medicine, Gynaecology \& Obstetrics

Journal of Stem Cells Research, Development \& Therapy

Journal of Surgery: Current Trends \& Innovations

Journal of Toxicology: Current Research

Journal of Translational Science and Research

Trends in Anatomy \& Physiology

Journal of Vaccines Research \& Vaccination

Journal of Virology \& Antivirals

Archives of Surgery and Surgical Education

Sports Medicine and Injury Care Journal

International Journal of Case Reports and Therapeutic Studies

Journal of Ecology Research and Conservation Biology 